\title{
A Modernidade da Gestão: Proposta de um Modelo de Estrutura Organizativa
}

* Depto. de Saneamento da Escola Nacional de Saúde Pública/Fiocruz, Rua Leopoldo Bulhões, 1480, $5^{\circ}$ andar, Manguinhos, 21041 - Rio de Janeiro - $R J$

** Depto. de Administração e Planejamento em Saúde da Ensp/Fiocruz

$\star \star \star$ A despeito dos autores deste trabalho terem restrições quanto à inclusão de recursos humanos pura e simplesmente nesta categoria.

\author{
Szachna Eliasz Cynamon* \\ Mário Antônio Sayeg**
}

\section{INTRODUÇÃO}

Planejamento e Administração, per se ou em conjunto, têm dado oportunidade, ao longo do tempo, a estudos que retratam sua abrangência e complexidade, seja conceitual, seja metodológica, seja de propostas de aplicação prática, que objetivam, finalisticamente, alcançar resultados favoráveis na gestão.

Há um contínuo evoluir nestes campos, constituindo-se em várias escolas que adotam referenciais integradores, de maior ou menor profundidade, quanto ao modo de conceber a organização, o pensar, agir e sentir da sociedade - o metassistema de um ou o coletivo de outros -, cujas propostas metodológicas visam à melhoria dos resultados na produção, com a mais adequada absorção de insumos, ${ }^{* \star *}$ a menor friç̧ão possível, ou seja, com a maior harmonia e bem-estar das pessoas que integram a organização.

A experiência acumulada, a integração e a reflexão têm revelado aspectos significativos do contexto de variáveis interdependentes até então submersas e negligenciadas.

A sociedade tem mudado e com ela as organizações. Daquelas estruturas formais do passado, em que prevalecem a rigidez e a verticalidade, para o desempenho, em menor ou maior extensão, das funções clássicas, vieram outras com maior atenção ao sociograma, de valorização do trabalho das variáveis. Surgiram propostas como a do botton side up, flexibilização de horários de trabalho, de carreiras, educação continuada, reciclagem, e outros benefícios conquistados.

É contemporânca a abordagem do tipo planejamento e administração estratégicos, onde as dinâmicas social e política do entorno e da própria organização assumem especial relevo. Além das variáveis organizacionais, que envolvem aspectos economicos informacionais e técnicos, destacam-se aquelas de naturera psicológica. Mais ainda, a contextualização da organização e de sua dinâmica incorpora variáveis sociolígicas e políticas, os cenários, os atores, 
as tendências de mudanças, componentes indispensáveis a quantos pretendam ver sua organização alcançar e manter a capacidade de atingir seus objetivos e metas.

Manter uma organização viva, dinâmica, cônscia de suas responsabilidades e papéis sociais, no ambiente onde prevalecem os elevados interesses de uma comunidade (até de uma nação), requer a permanência de mecanismos de planejamento e de gestão ágeis, criativos, flexíveis, dos quais emanem propostas seguras, de fácil aceitação e segura aplicação.

Algumas organizações, nem tanto as mais complexas, tentam superar conflitos. Um dos mais repetitivos diz respeito ao tradicionalismo conservador das estruturas-meio, que se apegam, em nome dos cânones da administração clássica, em manter candelabros de serviços e seçōes, versus a simplificação que facilmente é alcançada nas atividades-fim. Nestas últimas, em que pese a divisão do trabalho, prevalece a simplificação organizacional, ainda mais quando é obtida a cooptação de talentos e de vontades. Podem ser alvo de críticas organizações onde exista um certo grau de ruptura com o formal. Até onde over lays na atividade-fim, fruto de empatias, de aceitação de objetivos estratégicos para o grupo e que coincidem com os da organização, não são favoráveis a curto e médio prazos? E o longo prazo não seria uma sucessão dos curtos prazos que deram certo e foram sendo ajustados em consonância com as mudanças políticas, sócio-culturais e econômicas do entorno?

Instituiçōes tem havido que ostentavam magníficas organizações, obedecendo a modelos administrativos os mais modernos da época, e não sobreviveram por anacrônicas, por inflexiveis, por inoperantes, por entrópicas. Excessivamente preocupadas com os niveis de autoridade, com O\&M, com os passos e procedimentos operacionais, com os departamentos, serviços e seções, criando-se estruturas muito pesadas de um lado e, do outro, propiciando o confinamento dos servidores. Vale dizer, em detrimento do convívio, da fácil e veraz circulação de informação, da ascensão por mérito, da voluntária aceitação e medulização de propostas institucionais e plena participação no esforço de produzir, modernizar e expandir.

Modernidade, se, de um de seus lados, requer a avaliação do passado para fins de influir no presente, para adaptação da organização, também é perscrutar o futuro. Não é mera 
*Zadig, em defesa de sua noiva Semira, sofreu profundo ferimento, próximo ao olho esquerdo. Formou-se um abscesso e, para tratá-lo, chamaram em Menfis "o grande médico Hermes que chegou com numeraso séquito, visitou o enfermo e declarou que este perderia a vista; predisse até o dia e a hora em que deveria ocorrer o nefasto acidente. Se fosse o olho direito - disse ele - eu poderia curá-lo, mas as feridas no olho esquerdo são incuráveis.

Toda Babilônia, lamentando o destino de Zadig, admirou a profundeza da ciência de Hermes. Dois dias depois, o abscesso revolveu-se por si mesmo; Zadig ficou completamente são. Hermes escreveu então um livro, em que lhe provou que não deveria ter sarado. " in Zadig e o Destino - Contos e Novelas de Voltaire - 11 Edição - 2: Impressão Livraria Globo - Porto Alegre 1960 (Tradução de Mário Quintana). tentativa de reduzir o futuro aos insights dos planejadores, formuladores de planos e programas ideais que podem não se realizar. Não é infreqüente verem-se trabalhos publicados a explicar o insucesso, que lembram o episódio do olho de Zadig, personagem de Voltaire.*

As tentativas de reduzir a identificação das variáveis do entorno àquelas classificadas como significativas e dependentes, por vezes, levam a negligenciar as forças emergentes, mais representativas das aspirações $\mathrm{e}$ interesses coletivos.

Nas organizações manifestam-se as lutas pelo Poder veladas ou ostensivas, decididas algumas vezes por usurpação ou outorga, em nome dos processos democráticos. Manipulam-se conceitos como o de "Povo no Poder" ou de "Poder do Povo".

Os escolhidos, mercê sua formação e do meio, assumem autoridade a ser exercida através e para grupos favorecidos, que abjuram da gestão para todos e com todos. Por negligência ou desinformação, esses gestores repelem parte maior ou menor do corpo funcional, daí resultando insatisfação, subutilização, falta de aderência aos compromissos institucionais, baixa produtividade etc. São conseqüências de uma chefia incompetente.

Paralelamente, há que considerar os aspectos inerentes à burocracia.

Segundo Kliksberg (2), na prática das organizações, existe a confluência de, no mínimo, três tipos de grupos, que são identificáveis e procuram moldar a organização segundo sua própria físionomia:

a) os intraburocráticos de pressão, que se coligam em torno de diferentes interesses setoriais e procuram fazer com que a organização avance na direção mais conveniente para eles;

b) os extemos à organização, que exercem pressões para que ela se oriente para seus objetivos;

c) a clientela, os beneficiários legítimos dos serviços de organização.

Cita Crozier, que analisa a luta pelo poder através do controle das "fontes de incertezas dentro de organizaçāo" (como as carreiras, níveis salariais, promoções etc - questões estas muito significativas para os vários níveis da organização e que devem permanecer numa área de "decisões obscuras", que aparentemente reforçam o poder de alguns). 
A visão anacrônica de uma política de pessoal tinha por um de seus principios o controle, contrastando com aquela que se quer contemporaneamente de "desenvolvimento de recursos humanos".

Os gerentes de organizações modernas devem estar em condiçōes de exercer atividades diversificadas, que muitas vezes escapam a uma rotina. Muitas divisões, reflete Motta (4), aparentemente confluíram do racional e metódico com interveniência do ilógico, intuitivo que, na verdade, teria por pano de fundo experiências pregressas acumuladas.

Propostas têm surgido de modernização com flexibilização, como diz Paulo Roberto Motta (5) Existem vários modelos recentes de flexibilidade estrutural que, apesar de significarem progressos acentuados, constituem-se ainda em pequenos desvios e escapismos à organização tradicional, isto é, mantêm a base da estruturação das tarefas. As propostas mais recentes procuram alterar essa base, criando-se um fundamento na estruturação de equipes, antes da definição de tarefas. Essas propostas alteram substancialmente perspectivas organizacionais que têm prevalecido até hoje: envolvem mudanças no todo organizacional.

Propõe Motta, neste mesmo trabalho, que a organização seja descentralizada e autonomista; redundante; diferenciada por objetivos e área geográfica; integrada por comunicaçōes intensivas; baseada em equipes.

Mais facilmente poderão ser implantados modelos flexíveis em instituições de ensino e/ou de pesquisa, onde há características básicas:

1 - seleção de pessoal com base em concursos, para aqueles vocacionados;

2 - oferta de carreiras;

3 - educação continuada na instituição e em outras com ativa participação do pessoal senior;

4 - contatos freqüentes interpessoais;

5 - circulação de informações - trabalhos científicos, normas, procedimentos e novas tecnologias.

\section{PROPOSTA DE MODELO DE ESTRUTURA} ORGANIZATIVA

Como foi comentado, os sistemas clássicos de organização administrativa funcionam com eficiência cada vez mais reduzida em muitas entidades, podendo ocorrer 
também em instituições modernas de ensino e pesquisa, como resultado da interveniência de diversos fatores, isolados ou agrupados, tais como:

1 - são muitos os elegíveis para postos de mando nestas instituições, que se consideram iguais entre seus pares;

2 - a crescente tendência de preencher as funções de mando através de processo eletivo, o que leva, na prática, à quebra da autoridade clássica, em decorrência de quem manda estar muito próximo do subordinado, que tem o poder do voto capaz de lhe conferir ou não o mandato. $\mathrm{O}$ fato se complica em muitas situações de jogo de interesses políticos em entidades públicas, onde, por vezes, é muito débil a competência para admitir ou demitir recursos humanos, havendo ainda o medo de perder vagas ou mesmo pessoas, ou atiçar a oposição de forças, levando à corrupção;

3 - a derrocada na prática de linhas de mando, quando os cargos são ocupados por profissionais mais jovens, que foram preparados ou mesmo cuja carreira se fez por estímulo e influência dos seniors que, no processo natural Turn over das chefias, vieram a ser substituidos, podendo ocorrer, por vezes, insatisfações de parte a parte;

4 - complexidade crescente de sistemas centralizados e falência na prática de execução de ordens e mandos;

5 - falência de órgãos tipo Conselho e Conselho Deliberativo, cujos membros são oficialmente subordinados à chefia, a qual devem aconselhar ou cujas propostas e atos lhes cabem julgar;

6 - falta de delegação efetiva de poderes que não é cumprida pelas instâncias superiores, principalmente no que diz respeito ao manuseio de recursos, admissão, substituição, transferência e demissão de pessoal;

7 - lacunas, morosidade e bloqueios do sistema de informação e comunicação compensados pela reunionocracia e seus excessos;

8 - efeitos negativos da reunionocracia, gerando o forte desperdício de tempo já tão curto dos chefes, e influindo sobremaneira sobre aqueles que não dispensam, apesar de estarem incumbidos de funções administrativas, a continuidade de sua participação em ações técnicas-fim;

9 - super ou subvalorização das atividades administrativas em detrimento ou prejuizo intolerável das atividadesfim ou vice-versa; 
10 - supervalorização dos profissionais graduados, como administradores e planejadores, às vezes ainda sem experiência, não-vocacionados, designados para o comando de ações técnicas, ou vice-versa, subvalorização dos profissionais graduados em administração e utilização dos experientes com suposta vocação;

11 - compromissos eleitorais, levando a posterior distorção da hierarquia, colocando o peso de voto de grupos, a subverter os níveis hierárquicos que devam ser preservados.

\section{A PROPOSTA}

O que se propõe é um sistema sem linhas de mando, com ações e responsabilidade atribuídas entregues, segundo livre aceitação da divisão de trabalho, vale dizer, voluntariamente, assim como das coordenações, sempre agindo dentro do princípio de consenso, desde a discussão dos aspectos conceituais dos programas, suas estratégias, responsabilidades e que resultam em:

1 - adesão e aderência voluntárias;

2 - coparticipação responsável e respeito à programação, diretrizes etc, dentro do compromisso empresarial voluntariamente aceito;

3 - liberdade de ação consensualmente aceita;

4 - respeito às ações realizadas;

5 - diretrizes, programas e, quando for o caso, planos debatidos e consensualmente aceitos, aderidos e aditados;

6 - quando e onde necessário, em função de divisão de trabalho, valer-se de instrumentos de adesão e aderência voluntária, como uma central CAAVES* e perpasse de UNILICONS," em substituição às antiquadas chefias e coordenações. Instituição de RECAAVES, " como locais de reflexão em oposição aos demais conselhos de toda ordem;

7 - substituir as linhas de mando pelos UNILICONS;

8 - as CAAVES, nos diversos níveis de agregação (adesão) e aderência, recebem os fluxos da comunidade, da Instituição maior e de sua própria assembléia, dentro de um espírito de uniāo; congregam os aderentes e leva-os a elaborar a ação e agir com o auxílio dos especialistas de apoio, através dos caminhos da União das Linhas de Informação e Canais de Comunicação (UNILICOM);
**UNILICOM - são os caminhos da união através de linhas de informação e canais de comunicação.

*CAAVES - centros de adesão e aderência voluntárias de execução.

$\star \star \star$ RECAAVES - assembléias de reflexão de CAAVES, para elaboração, avaliação e revisão de diretrizes de ação. 
9 - os diversos níveis de agregação (adesão) e aderência substituem os antiquados setores, seções, divisões, centros, departamentos;

10 - todo o sistema funciona com o moderno UNILICOM, que repassa todas as CAAVES (células, órgãos e ação final). Ele interliga, amalgama e é o motor da produção;

11 - captadas as necessidades através do UNILICOM, as CAAVES chegam às fontes de produção, alimentam-se e movimentam os fatores e, mais uma vez através do UNILICOM, chega-se ao apoio coordenado das CAAVES e, assim, de forma democrática, voluntária e solidária, cresce a produção e o produto que retorna aos pontos de necessidade.

Ensino e pesquisa requerem e são filhos da liberdade e a reforçam e engrandecem.

O conhecimento é um dos tripés da Independência, ao lado da política e da economia.

O conhecimento é obtido como fruto da liberdade e, por sua vez, a cimenta.

Não há igualdade na natureza, mas, com o respeito às individualidades, consegue-se manter uma cadeia heterogênea harmônica, alimentar o necessário e produzir para o crescimento e formação de novas cadeias harmônicas.

A liberdade, com seus limites naturais, conseqüentes ao pensar, agir e sentir grupal, é essencial às empresas, mas especialmente àquelas devotadas ao ensino e pesquisa.

Naturalmente há que se evitar os excessos através do diálogo, do consenso, da adesão e da aderência em ações e produtos consentidos e, após, aceitos.

\section{RESTRIÇÕES}

Para a funcionalidade e eficiência do sistema, devem ser observados preceitos básicos:

1 - adesão e aderência aos princípios finalísticos institucionais, a fim de haver participação e cobertura institucional;

2 - a adesão e aderência a todo e qualquer projeto, embora sejam voluntárias, obrigam o aderente ao cumprimento do ajustado, sob pena de exclusão do projeto e, sucessivamente e progressivamente, a maiores exclusões nos casos de reincidência que podem levar, no final, à exclusão da Instituição; 
3 - implantação de um sistema racional e funcional das UNILICONS, com o indispensável método racional e funcional de registro;

4 - solidariedade das CAAVES nos diversos níveis, de modo a se prestar socorro mútuo e apoio institucional, quando necessário, não como uma forma de favor, mas de obrigação inerente ao sistema, independente de aspectos de corporativismo profissional, funcional, de grupos políticos; de religião, cor ou origem ou de grupos de amizade;

5 - sistemas de crédito, de emulação e mérito;

6 - valorização profissional e de empenho, com estímulos ao aperfeiçoamento técnico permanente;

7 - participação equitativa no produto, sob diversos aspectos, como, por exemplo, reconhecimento do mérito, coletivo e individual e de autoria até de participação material nos resultados;

8 - compromisso institucional;

9 - avaliação e reavaliação de atitudes e resultados;

10 - liberdade de crítica em todos os níveis e sob todos os aspectos, efetuada de forma ética.

\section{REFEREANCIAS BIBLIOGRÁFICAS}

1 - MARCH, J.G.; SIMON, A.A. - Teoria das Organizaçôes tradução de Hugo Warlich - 5: ed. - Rio de Janeiro, Editora Fundação Getulio Vargas, 1981.

2 - KLIKSBERG, Bernardo - A gerência na década de 90, Revista de Administração Pública - Rio de Janeiro, 22 (1): 59 85, Jan/Mar. 1988.

3 - MATOS, R. de A. - Para que modernizar a Organização Pública? Revista de Administração Pública - Rio de Janeiro, 22 (3): 22 - 26, Jul./Set. 1988.

4 - MOTTA. P. R. - Razão e intuição: recuperando o ilógico na teoria da decisão gerencial - Revista de Administração Pública - Rio de Janeiro, 22 (3): 77 - 94, Jul./Set. 1988.

5 - MOTTA, P.R. - Flexibilidade Estrutural: a Implosão do Organograma e as Bases de Organização Atomizada e Holográfica. Mimeo. 